\title{
Abordagem teórica dos condicionantes da formação e consolidação dos parques tecnológicos
}

\author{
Alexandre Augusto Pereira Gaino ${ }^{\mathrm{a} *}$, João Batista Pamplona ${ }^{\mathrm{b}}$ \\ a*alexandre.augusto@fsa.br, FSA, Brasil \\ bpamplona@pucsp.br, PUC-SP, Brasil
}

\begin{abstract}
Resumo
0 artigo discute as condições teóricas para a instalação e consolidação dos parques tecnológicos, mecanismos utilizados na promoção da inovação tecnológica e do desenvolvimento regional, alvo de diversas iniciativas de políticas públicas na atualidade. Para a consecução desse objetivo foi adotada uma abordagem teórica e exploratória, por meio de revisão bibliográfica, em especial de referências internacionais. 0 artigo apresenta e analisa diversos conceitos e definições de parque tecnológico e constata que essa diversidade decorre das diferentes realidades regionais e das variadas motivações dos stakeholders. 0 papel dos parques tecnológicos no desenvolvimento regional assume múltiplas feições em decorrência dos distintos interesses dos atores envolvidos em sua instalação. 0 artigo enfatiza e adverte que há importantes limitações da ideia de que o sucesso do parque depende fundamentalmente da capacidade de cooperação e mobilização de recursos por parte dos agentes envolvidos.
\end{abstract}

Palavras-chave

Parques tecnológicos. Desenvolvimento regional. Inovação tecnológica. Instituições de ciência e tecnologia.

\section{Introdução}

Com o objetivo de superar os desafios postos pelo processo de globalização e pela competição cada vez mais acirrada, as regiões têm assumido novos desafios e têm desenvolvido diferentes programas e projetos para os quais convirjam os interesses dos diversos atores envolvidos, públicos e privados, possibilitando maior interação entre eles de forma mais efetiva e menos burocrática.

Como consequência do protagonismo das regiões, diversas experiências são empreitadas no sentido de promover a inovação e o desenvolvimento econômico em âmbito territorial. Essas iniciativas têm assumido as seguintes formas institucionais de arranjos locais: distritos industriais, incubadoras, parques tecnológicos, arranjos produtivos locais, entre outras.

Em especial, os parques tecnológicos, ao permitirem a integração de diferentes instituições territoriais e nacionais, têm se apresentado como possivel solução para o problema da promoção de inovação tecnológica e do crescimento econômico em âmbito territorial. Surgidos originalmente de forma espontânea no contexto da interação entre universidades e empresas, os parques tecnológicos proliferaram pelo mundo nas décadas de 1970 e 1980 por meio de políticas públicas, como resposta à mudança técnico-econômica do sistema de produção (do fordismo para o pós-fordismo). Os parques tecnológicos ganham destaque tanto pela amplitude de atendimento às empresas e demais organizações locais quanto por sua necessidade de articulação territorial e supraterritorial ou, ainda, pelo volume de recursos necessários para sua implantação e desenvolvimento. Entretanto, a literatura empírica internacional tem demonstrado que as muitas experiências com parques tecnológicos não têm alcançado os resultados esperados.

0 presente artigo discute as condições necessárias, do ponto de vista teórico, para a instalação e desenvolvimento de parques tecnológicos. 0 principal objetivo é contribuir com a discussão a respeito dos limites do uso desse mecanismo como forma de promover o desenvolvimento econômico e a geração 
de inovações nas regiões. Com este intuito, o artigo está dividido em três seções além desta introdução e da conclusão.

Na segunda seção são apresentados os conceitos e definições pertinentes - verifica-se uma grande diversidade de definições e terminologias decorrentes das adaptações dos parques tecnológicos às diferentes realidades regionais e às diversas motivações de seus stakeholders.

$\mathrm{Na}$ seção três é analisada a interação entre o território e o potencial de geração de inovações, para tanto, inicia-se por uma exposição das mudanças estruturais da economia mundial (globalização e mudança de paradigma técnico-econômico) nas últimas décadas e o efeito delas sobre o papel das regiões como catalisadoras do processo de inovação. A seção finaliza com uma discussão sobre os interesses dos atores regionais na instalação desses instrumentos em seu território.

A seção quatro discute as condições necessárias para a instalação dos parques tecnológicos, com especial destaque para a temática da capacidade de criação ou mobilização de recursos por parte dos agentes envolvidos. Por fim, as conclusões apresentadas procuram alertar para as restrições locacionais para a instalação de parques tecnológicos e as limitações desses empreendimentos para o desenvolvimento regional.

\section{Conceitos e definições de parque tecnológico e de outros mecanismos de promoção da inovação localizada}

Diversas experiências para o desenvolvimento econômico em âmbito territorial têm sido identificadas. A literatura nacional e internacional apontam as seguintes formas institucionais de arranjos locais: distritos industriais, arranjos produtivos locais, incubadoras de empresas, parques tecnológicos, entre outras. Segundo Cassiolato e Lastres (2003a), os distritos industriais referem-se a aglomerações de empresas com elevado grau de especialização e interdependência, seja de caráter horizontal (entre empresas de um mesmo segmento, ou seja, que realizam atividades similares) ou vertical (entre empresas que desenvolvem atividades complementares em diferentes estágios da cadeia produtiva). Ainda, segundo o autor, os arranjos produtivos locais são aglomerações territoriais de agentes econômicos, políticos e sociais, interrelacionados, englobando empresas ligadas a uma cadeia produtiva e entidades e organizações públicas e privadas com as quais as empresas se relacionam (CASSIOLATO; LASTRES, 2003a).
As incubadoras de empresas e os parques tecnológicos pertencem à mesma família de políticas de apoio à inovação e empreendedorismo. Tais mecanismos privilegiam as sinergias entre diferentes atores, a criação de ambiente pró-inovação e a implantação de estruturas multi-institucionais de fomento à agregação de valor à produção local/regional. Entretanto, as incubadoras se apresentam como instrumento mais limitado em termos físicos e têm como foco o atendimento exclusivo de micro e pequenas empresas e não necessariamente de base tecnológica. Já os parques tecnológicos referem-se predominante a aglomerações de empresas de base tecnológica, que podem ser pequenas ou não, articuladas a universidades e centros de pesquisa e desenvolvimento (P\&D), possibilitando sinergias decorrentes da proximidade entre os atores (VEDOVELLO, 2000).

Para Barbieri (1995), os parques tecnológicos selecionam as empresas que pretendem nele se instalar e oferecem serviços e instrumentos de cooperação baseados eminentemente no caráter técnico-científico. Esses fatores os diferenciam dos distritos industriais tradicionais.

Há outras denominações utilizadas para parques tecnológicos que variam no tempo e conforme a região ou país de análise, sendo as mais conhecidas: cidade científica, cidade tecnológica, tecnópolis, parque científico, parque de pesquisa, entre outras. Para alguns autores, esses termos são determinados pela região de instalação dos parques: o termo parque científico é mais usado nos países da Europa; parque de pesquisa é a denominação que prevalece nos EUA; e parque tecnológico é o termo utilizado na Ásia (LINK; SCOTT, 2007).

Apesar de essas denominações serem utilizadas na maioria da literatura especializada como sinônimos, há algumas tentativas de especificar cada termo, para as diferentes experiências em operação no mundo. A European Commission (2007) estabelece especificações que serão vistas a seguir.

Um parque científico (science park) é um parque empresarial no qual a principal atividade da maioria dos estabelecimentos instalados é a pesquisa e/ou o desenvolvimento de novos produtos ou processos. Nesse caso, a produção decorrente, frequentemente, é realizada em outro local. Um parque de pesquisa (research park) difere de um parque científico pois proíbe em seu interior a fabricação, exceto para a produção de protótipos, ou seja, a ênfase de atuação recai sobre as atividades de pesquisa e desenvolvimento experimental, exclusivamente. Nesse sentido, pode ser encarado como uma forma especial de um parque de ciência, com ênfase nas obrigações contratuais de propriedade e/ou operacionais relacionadas à transferência de tecnologia entre a empresa e uma ou 
mais universidades ou outras instituições de ensino superior e de pesquisa científica (EUROPEAN..., 2007).

Um parque tecnológico ou pólo tecnológico é uma zona de atividade econômica composta por universidades, centros de investigação, unidades industriais e terciárias que realizam suas atividades baseadas em pesquisa e desenvolvimento tecnológico. Parques tecnológicos são limitados em área geográfica mas mantêm ligações em rede com as grandes empresas e com a infraestrutura de pesquisa pública e privada, tanto em nível nacional quanto internacional, e sua ênfase extrapola as atividades de P\&D, sendo permitidas e estimuladas atividades de produção e comercialização de bens e serviços (EUROPEAN..., 2007).

Além das diferentes denominações, também não há uma definição única que possa ser aplicada a todos os parques tecnológicos. Segundo Vedovello (2000), isso é devido ao fato de esses mecanismos apresentarem uma diversidade e uma heterogeneidade muito grande em relação a seu modelo ideal. A European Commission (2007) argumenta que a história singular de formação de cada parque tecnológico determinou diferentes formatos de implantação nos diversos países, dos quais decorre a disparidade de definições.

A United Kingdom Science Park Association - UKSPA, instituição criada em 1984, que possuía aproximadamente 100 associados em 2002, define parque tecnológico como:

\section{[...] uma iniciativa de suporte empresarial empenhada na transferência de conhecimentos tecnológicos e de negócios para as pequenas e médias empresas, cujo principal objetivo é incentivar e apoiar as start-ups e a incubação de empresas inovadoras de alto crescimento baseadas em conhecimento, por meio da prestação de serviços de infraestrutura e de apoio, incluindo relações de colaboração com agências de desenvolvimento econômico e ligações formais e operacionais com centros de excelência como universidades, institutos de ensino superior e institutos de pesquisa (UKSPA apud INTERNATIONAL..., 2010,s/p, tradução nossa).}

A ênfase dessa definição está na geração de conhecimento e no papel central de universidades e centros de pesquisa e na interação que pode ser estabelecida entre esses agentes e empresas. Segundo Vedovello (2000), a abordagem da UKSPA possui como elementos centrais as "[...] ligações operacionais e formais com universidades, centros de pesquisa e/ou instituições de ensino superior [...]" que possibilitam ao parque desempenhar sua função de gestão relacionada à "transferência de tecnologia e habilidades de negócios", com o objetivo de encorajar a formação e o crescimento de empresas localizadas dentro de seu espaço físico.
Já a definição oficial da International Association of Science Parks - IASP (INTERNATIONAL..., 2010), instituição também criada em 1984 que conta atualmente com 375 membros de cinco continentes, considera um parque tecnológico como:

\section{[...] uma organização gerenciada por profissionais especializados, cujo objetivo é incrementar a geração de renda e bem-estar da sua comunidade, por meio da promoção da cultura de inovação e da competitividade dos empreendimentos e das instituições inovadoras a ela associados. Para a consecução desses objetivos, o Parque Científico gerencia e estimula o fluxo de conhecimento e de tecnologia entre universidades, instituições de P\&D, empresas e mercados, facilitando a criação e o crescimento de empresas inovadoras por meio da incubação e de spin-offs, e fornece outros serviços de alto valor agregado aliados a um espaço físico e serviços de apoio de qualidade [...] (INTERNATIONAL..., 2010, s/p, tradução nossa).}

Em comparação com a definição da UKSPA, a definição da IASP é mais abrangente, pois alia transferência de tecnologia, fomento à criação de novas empresas inovadoras, espaços e infraestrutura de qualidade para o desenvolvimento tecnológico e destaca o objetivo de incrementar a renda e o bem-estar da comunidade.

Por outro lado, a Association of University Research Parks - AURP, criada em 1986, define parques universitários de pesquisa como sendo:

[...] um empreendimento que dispõe de áreas e prédios para a instalação de centros de pesquisa e desenvolvimento públicos e privados, de empresas de base tecnológica e de serviços de apoio, possibilitando o desenvolvimento de parcerias com universidades e institutos de pesquisa, de maneira a promover a transferência tecnológica e as atividades de P\&D pelas universidades em parceria com a indústria, auxiliando no crescimento de novos empreendimentos e promovendo o desenvolvimento econômico [...] (AURP apud INTERNATIONAL..., 2010, s/p, tradução nossa).

A definição da AURP focaliza o papel das transferências tecnológicas como geradoras de externalidades positivas, entre as universidades, empresas e comunidade em geral. Nesse sentido, as parcerias estimuladas dentro dos parques universitários de pesquisa são o ponto relevante desses empreendimentos.

Link e Scott (2006) utilizam também o termo parques universitários de pesquisa e com base em uma visão geral das diversas definições apresentadas pela literatura, os autores propõem a seguinte definição para essa expressão:

[...] conjunto de organizações de base tecnológica, localizado dentro ou próximo a um campus 
universitário, cujo objetivo é beneficiar-se do conhecimento e das pesquisas da universidade. A universidade espera não só gerar a transferência de conhecimento, mas desenvolver o conhecimento de forma mais eficaz, dada a associação com os integrantes do parque [...] (LINK; SCOTT, 2006, p. 44, tradução nossa).

A definição utilizada por Link e Scott (2006) está baseada no papel das universidades na transferência de conhecimento, incluindo a disponibilidade de espaço físico para a instalação das organizações de base tecnológica.

No caso brasileiro, a Associação Nacional de Entidades Promotoras de Empreendimentos Inovadores - ANPROTEC, criada em 1987 e que possui hoje 272 associados, considera os parques tecnológicos como sendo:

[...] um complexo produtivo industrial e de serviços de base científico-tecnológica planejado, de caráter formal, concentrado e cooperativo, que agrega empresas cuja produção se baseia em pesquisa tecnológica desenvolvida nos centros de P\&D vinculados ao parque. Trata-se de um empreendimento promotor da cultura da inovação, da competitividade, do aumento da capacitação empresarial, fundamentado na transferência de conhecimento e tecnologia, com o objetivo de incrementar a produção de riqueza de uma região [...] (ASSOCIAÇÃO..., 2003, p. 46).

Essa definição remete à ideia de um complexo produtivo-industrial planejado, articulado e concentrado, caracterizado por um espaço delimitado com infraestrutura de promoção de empresas de alta tecnologia e cujo principal objetivo é o desenvolvimento regional.

Segundo Vedovello, Judice e Maculan (2006), as razões para a diversidade de conceitos e definições dos parques residem na busca e inserção de diferentes atores sociais - tais como universidades, institutos de pesquisa, prefeituras, governos estaduais e federal, agentes financeiros, empresas de diferentes portes e empreendedores - para o engajamento nessas iniciativas. Nesse sentido, observa-se, de forma geral e ao longo do tempo, certa flexibilização na conceituação de parques tecnológicos que se mostra adequada para abrigar e acomodar os diferentes stakeholders com seus diferentes objetivos, expectativas e interesses.

Apesar das diversas conceituações utilizadas para parques tecnológicos, a literatura aponta certos denominadores comuns: os parques tecnológicos são empreendimentos que reúnem empresas de alta tecnologia, tanto focadas em produtos quanto em serviços, e oferecem a oportunidade para um elevado grau de cooperação institucional entre universidades e indústrias, constituindo-se loci privilegiado composto, normalmente, por infraestrutura física e organizacional de articulação e de criação de conhecimento visando o processo de inovação. Tais empreendimentos apresentam como objetivos básicos: geração de empregos, estabelecimento de novas empresas, estímulo à interação universidade-empresa e difusão de novas tecnologias.

\section{Desenvolvimento regional, inovação e o papel dos parques tecnológicos}

0 aumento do comércio internacional, nas últimas décadas, somado à intensificação do fluxo de capitais, teve como consequência uma ampla reestruturação produtiva, a qual alterou de forma profunda as relações de produção, comercialização e distribuição. Esse processo teve como condição sine qua non o desenvolvimento tecnológico, em especial nas áreas de tecnologia da informação e comunicação. Ao mesmo tempo, permitiu a ampliação das tecnologias em escala global (CASSIOLATO; LASTRES, 2003b).

0 impacto da mudança de paradigma técnicoeconômico em âmbito planetário provoca naturalmente drásticas mutações e rearranjos nas estruturas de produção ou nos mercados. A configuração das principais cadeias produtivas vem sendo modificada, seja no redesenho das estruturas organizacionais das firmas, seja na substituição de componentes, partes e peças nacionais por importados, seja na incorporação de novas tecnologias (SPOLIDORO, 1997).

A partir da década de 1960, uma sociedade que baseia seus processos de produção, circulação e acumulação no conhecimento e na informação emerge e intensificam-se, paralelamente, os processos de globalização por meio dos quais as políticas protecionistas dos países são gradativamente substituídas pela liberalização de seus mercados.

Sob o ponto de vista das regiões, o fim do protecionismo e das restrições à entrada de novas empresas e investimentos internacionais possibilita que elas, agora como protagonistas, por meio de suas diferenciações e vantagens locacionais, atraiam investimentos para consolidação e reconfiguração do desenvolvimento regional.

No bojo dessa relação dialética que combina o hiperespaço da circulação de capital com a recriação da localidade ressurge o discurso acadêmico e a prática política da ação local na busca da construção econômica e social, redefinindo o lugar da localidade como locus da vida econômica e social [...] (DINIZ, 2001, p. 3).

Trata-se, assim, de um novo cenário regional para o crescimento brasileiro, com o surgimento de novas áreas industriais e eixos de desenvolvimento, 
que redesenham a configuração territorial da atividade econômica. Nessa nova rodada do jogo do desenvolvimento, é sobretudo a agilidade e a eficácia em reciclar-se e reposicionar-se nos circuitos do mercado, interno ou externo, que determinam a perspectiva de sucesso ou fracasso dos capitais e, por extensão, das economias regionais.

Nesse contexto, o êxito das regiões depende de sua capacidade de especialização e de criação de vantagens comparativas efetivas e dinâmicas, decorrentes do estoque de atributos e da competência local de promoção continuada de inovação. 0 que, por sua vez, é decorrente da capacidade empresarial em promover atividades de pesquisas e desenvolvimento (P\&D) e identificar novos produtos e processos, assim como da capacidade local de cooperar e aprender (DINIZ; GONÇALVES, 2005).

Dierdonck, Debackere e Rappa (1990) sugerem que a cooperação universidade-empresa e, consequentemente, a transferência de conhecimento, raramente ocorre de forma natural, possuindo barreiras de interação, decorrentes da natureza, modus operandi e objetivos de cada um dos envolvidos. Para a efetivação da transferência de tecnologia, os autores argumentam a necessidade da criação de mecanismos para essa transferência, tais como consórcios de pesquisa, joint ventures e parques tecnológicos, os quais possibilitariam a aproximação do setor produtivo e do setor acadêmico e a compatibilização de seus objetivos.

Dessa forma, os parques tecnológicos têm se apresentado como solução para a integração de diferentes agentes sociais, tanto na dimensão territorial quanto nacional, incluindo universidades, pequenas e grandes empresas (VEDOVELLO; JUDICE; MACULAN, 2006), para a promoção da inovação, competitividade e o crescimento econômico. Essa solução facilita o acesso das empresas aos conhecimentos gerados pelas universidades, por meio da transferência de tecnologia, configurando-se em ambientes catalisadores para a transformação de pesquisa em produtos (LINK; SCOTT, 2006; 2007; LINDELÖF; LÖFSTEN, 2002, 2004). Além disso, por meio de efeitos de transbordamento (spillovers), os parques tecnológicos têm atuado como incubadoras de projetos inovadores desenvolvidos dentro das universidades, propiciando um ambiente favorável para o florescimento e desenvolvimento de spin-offs.

Para Link e Scott (2007), os parques tecnológicos permitem a minimização dos custos de informação e de procura de tecnologias desenvolvidas a serem aplicadas no processo produtivo das firmas pertencentes ao parque. Sob o ponto de vista da oferta, os parques possibilitam às universidades a existência de um canal de distribuição das tecnologias por ela desenvolvidas, assim como a proximidade com a indústria reduz os riscos de desenvolvimento e propicia um interessante canal de informações, no qual problemas enfrentados pela indústria podem se tornar interessantes linhas de pesquisa para a academia. Além disso, os parques geram maiores possibilidades de alocação do capital humano, representado pelos alunos graduados, pesquisadores e professores em tempo parcial vinculados à universidade.

Segundo Layson, Leyden e Neufeld (2008), os parques tecnológicos permitem que as comunidades alavanquem o crescimento econômico de base tecnológica por meio da redução de custos de transação para as empresas de alta tecnologia, especialmente custos associados ao acesso a trabalho altamente qualificado. Complementarmente, Siegel, Westhead e Wright (2003a) argumentam que ao reduzir a incerteza e os custos de transação e ao propiciar um contexto favorável para a aquisição e transferência de informações e conhecimentos, os parques tecnológicos fornecem os recursos essenciais ao surgimento e desenvolvimento de empresas de alta tecnologia.

No contexto da globalização econômica e, consequentemente, na competição internacional baseada na constante busca de vantagens competitivas, o conhecimento tácito, caracterizado pela dificuldade de codificação, se torna um diferencial precioso. Percebe-se que tais conhecimentos somente podem ser transmitidos por meio de contatos face a face, que pressupõem a proximidade física (VARGAS, 2002). Nesse sentido, os parques tecnológicos, ao representarem um conjunto específico de configurações institucionais e organizacionais territorialmente definidos, propiciam as condições para que a transmissão de conhecimentos tácitos se desenvolva entre os seus participantes.

Geenhuizen e Soetanto (2008) argumentam que os parques tecnológicos fazem parte de um conjunto de políticas que servem para ampliar o desenvolvimento territorial de atividades econômicas baseadas no conhecimento, constituindo-se em um instrumento do sistema local de inovação (FUKUGAWA, 2006). Para Lindelöf e Löfsten (2003), os parques tecnológicos são mais do que instrumentos de promoção da inovação e empreendedorismo. Eles se configuram como ambientes de vivência que orientam e estimulam comportamentos específicos em seus participantes, propiciando a formação de processos sociais e institucionais integrados (por exemplo, redes de cooperação) de estímulo à criatividade e inovação (LINDELÖF; LÖFSTEN, 2004).

Complementarmente, os parques podem se caracterizar como elos de ligação (hubs) para a inserção das empresas apoiadas em redes de inovação supraterritoriais. Tal fato possibilita às empresas instaladas no parque desenvolverem competências e tecnologias que dificilmente seriam implementadas caso não participassem de redes de inovação disponibilizadas pelos parques tecnológicos. Além disso, o papel de hub desempenhado pelo parque aprimora a capacidade de as empresas nele instaladas 
identificarem oportunidades e mudanças estruturais do ambiente econômico e tecnológico. Em consequência, evitam-se os riscos relativos ao enclausuramento do conhecimento e da inovação e possibilita-se a mudança de trajetória tecnológica, potencializando os processos de aprendizagem cooperativos visando inovações necessárias para a competitividade e desenvolvimento das firmas, para as quais as fontes externas assumem importância primordial na dinâmica da mudança tecnológica dos atores locais (VARGAS, 2002).

0 papel dos parques varia de acordo com os atores envolvidos. As universidades e institutos de pesquisa participam de parques tecnológicos como forma de solucionar problemas relacionados à insuficiência de recursos financeiros para atividades de pesquisa (VEDOVELLO, 2000). Dentre seus focos de interesse no empreendimento encontram-se: a comercialização de resultados de pesquisas anteriores, retorno financeiro proveniente da transferência de tecnologia para as empresas, ampliação do mercado de trabalho e da oportunidade de vincular professores e estudantes em atividades de P\&D em conjunto com o setor produtivo (VEDOVELLO; JUDICE; MACULAN, 2006; LINDELÖF; LÖFSTEN, 2002; LINK; SCOTT, 2006). Além disso, os parques têm se mostrado como uma boa forma de utilização de terras subtilizadas pelas universidades e como ação entre ela e a comunidade para a promoção do desenvolvimento econômico regional (GEENHUIZEN; SOETANTO, 2008).

Os grupos formados por empresários e os chamados acadêmicos-empresários são estimulados a participar dos parques tecnológicos em virtude das vantagens de proximidade e interação com instituições de ensino e pesquisa e com as demais empresas instaladas, da possibilidade de utilização compartilhada de equipamentos das universidades e demais parceiros, além da utilização de recursos humanos altamente qualificados disponiveis e do acesso a conhecimentos e informações de negócios (VEDOVELLO, 2000; GEENHUIZEN; SOETANTO, 2008; LINK; SCOTT, 2006). Além disso, pesquisas empíricas sugerem que empresas participantes em parques tecnológicos apresentam maior produtividade em projetos de desenvolvimento tecnológico (SIEGEL; WESTHEAD; WRIGHT, 2003b). As empresas instaladas em parques tecnológicos também usufruem vantagens referentes à percepção do mercado tais como endereço de prestígio e efeitos de imagem associados ao fato de o mercado considerar que as empresas instaladas em parques encontram-se em posição de vantagem em relação aos concorrentes; também os parceiros e funcionários sentem-se mais motivados por estarem participando de uma empresa com "prestígio" (FERGUSON; OLOFSSON, 2004).

Já governos, autoridades e agências de desenvolvimento compartilham da percepção da existência de oportunidades na comercialização de produtos baseados no conhecimento local e constituição de uma imagem positiva para a região (GEENHUIZEN; SOETANTO, 2008), da geração de emprego de alta qualificação e renda, do estímulo à constituição e desenvolvimento de empresas de base tecnológica e da convicção de que tais empreendimentos podem ser utilizados para a revitalização de territórios economicamente deprimidos (VEDOVELLO, 2000).

No caso de países em desenvolvimento, como o Brasil, a implantação de experiências desse tipo em regiões atrasadas ou estagnadas objetivando a reconversão das localidades encontra barreiras para se efetivar uma vez que tais regiões são precárias em termos de infraestrutura física e social, as quais proveriam as condições necessárias. Dessa forma, a implantação de alguns desses empreendimentos no Brasil tem se caracterizado pela geração de desenvolvimento tecnológico excessivamente ilhado, com poucos efeitos no tecido econômico e urbano e sem efeitos multiplicadores regionais (MEDEIROS, 1995).

Outros atores importantes na formação e consolidação dos parques tecnológicos são os agentes financeiros e venture capitalists, quepossuem o interesse em investir em empresas de alta tecnologia que apresentem retorno financeiro potencial elevado e crescimento acelerado (VEDOVELLO, 2000). Para esse grupo, o parque funcionaria como um instrumento de mitigação dos riscos envolvidos nas operações financeiras.

Por fim, existe o grupo formado pelos desenvolvedores imobiliários que vislumbra o parque tecnológico como oportunidade de investimento imobiliário, por meio do arrendamento ou da venda de terrenos e instalações para as empresas que nele pretendem se instalar (GEENHUIZEN; SOETANTO, 2008). Para esse grupo, a formação de redes de cooperação entre empresas e/ou com os institutos de ciência e tecnologia não é uma condição sine qua non para a formação do empreendimento, sendo que o essencial é a infraestrutura e a localização do parque tecnológico.

\section{Condicionantes da formação e consolidação dos parques tecnológicos}

Embora haja diferenças operacionais decorrentes das particularidades de cada um entre as diversas experiências internacionais de parques tecnológicos, especialmente em relação aos diferentes atores envolvidos e seus múltiplos interesses, é possível identificar uma combinação de fatores-chave que podem ser determinantes para a instalação e desenvolvimento de um parque em uma determinada localidade. 
Alguns autores sugerem que não serão mais os locais dotados de recursos que irão atrair as empresas e gerar o crescimento correspondente do emprego, mas os locais capazes de mobilizar os recursos de que as empresas necessitam [...] (LOGAN; MOLOTCH, 1987 apud APPOLD, 2004, p. 226, tradução nossa).

\section{Como argumenta Barquette (2002):}

Os atuais sítios de implantação dos centros de alta tecnologia formaram-se sob condições históricas e circunstâncias específicas e sua reprodução em outros locais depende da confluência favorável de uma gama de fatores - instituições, recursos, formas de interação social, cultura etc. - que conferem grande complexidade ao processo. (p. 102).

Nesse sentido, as regiões de instalação dos parques tecnológicos apresentam economia externa que afetaria as decisões locacionais por parte das empresas, assim

[...] os parques tecnológicos institucionalizam, ou ao menos representam, as economias externas de localização, decorrentes da aliança indústriauniversidade-governo [presentes no território] (MASSEY; QUINTAS; WIELD, 1992, apud APPOLD, 2004, p. 226).

Porém, como alerta Appold (2004), a criação de parques tecnológicos não seria resultado exclusivamente de coalizões de elites com capacidade de mobilizar recursos locais, e não de locais difusos, com este objetivo, mas sim consequência das características da região de instalação, dentre as quais as interações entre diferentes agentes locais seriam apenas uma das condições necessárias que tornariam o crescimento baseado em conhecimento mais provável.

Dierdonck, Debackere e Rappa (1990) concluem que os parques tecnológicos são consequência de um desenvolvimento tecnológico regional anterior, em outras palavras, existem precondições importantes para o sucesso de empreendimentos desse tipo. Por exemplo, Dorfman (1983) apud Dierdonck, Debackere e Rappa (1990) fornece três grupos de fatores que estimularam o desenvolvimento de um cluster de alta tecnologia em Massachusetts: presença de recursos físicos locais (mão de obra, infraestrutura tecnológica, capital de risco, custos relativamente baixos, transporte aéreo, atraentes bairros residenciais com fácil acesso ao local de trabalho); as economias externas de escala; e o empreendedorismo das novas empresas.

Assim, uma primeira condição necessária para a instalação e desenvolvimento de um parque tecnológico é a existência de uma infraestrutura mínima composta de áreas residenciais e empresariais disponíveis para a instalação do parque e a recepção dos empresários e funcionários das empresas que irão se instalar. Tais áreas devem ser providas de saneamento básico e urbanismo, elevada qualidade ambiental, facilidades de transportes, em especial proximidade de aeroportos e sistemas de telecomunicações de voz e dados de alta velocidade.

Outro fator de relevância para a implantação de um empreendimento dessa natureza é a construção de amenidades e sustentabilidade ambiental, englobando abundantes serviços de recreação e cultura que, segundo Castells e Hall (1994), são essenciais para atrair e fixar a mão de obra de qualificação elevada. Por outro lado, como argumentam Scott e Storper (1988, p. 41), as regiões receptadoras das novas indústrias de tecnologia, no caso norte-americano, não são definidas por atributos socioespaciais do tipo qualidade de vida, uma vez que, como os autores explicam, essa condição não é "uma categoria universal, mas sim uma categoria construída politicamente". Tal decisão locacional é prerrogativa da empresa, que busca, entre outras coisas, incentivo fiscal e tributário, além de atividade sindical insipiente.

Observa-se, ainda, a necessidade de o território apresentar uma escala mínima de aglomeração empresarial e densidade urbana que possibilite a geração de retornos externos crescentes de escala, por meio da infraestrutura física e de aprendizagem instalada, assim como da presença de instrumentos de incentivo à sinergia e cooperação dos agentes (DINIZ; SANTOS; CROCCO, 2006). Nesse sentido, a relevância do parque para a indução aos encadeamentos produtivos vai depender da estrutura industrial e do mercado de trabalho da região. Como argumentam os autores:

Os impactos potenciais [do parque para a região] seriam a localização de atividades industriais no entorno que poderiam se beneficiar de encadeamentos para trás com as empresas $\mathrm{P} \& \mathrm{D}$ do parque, com efeito posterior de indução à localização de serviços modernos ligados à produção (DINIZ; SANTOS; CROCCO, 2006, p. 99).

A escala mínima de aglomeração para instalação de um parque tecnológico corresponde à existência de um tecido produtivo de certo tamanho, assim como um mercado de trabalho já instalado no território, incluindo a oferta de serviços empresariais avançados tais como consultorias, assessorias técnicas e de manutenção mas que, porém, vá além dessas empresas do terciário avançado. Preferencialmente, essas empresas devem possuir algumas características desejáveis a fim de possibilitar a interação com as ingressantes no parque ou mesmo com a infraestrutura de conhecimento fomentada pelo empreendimento.

Outra condição necessária seria a existência de universidades e centros/institutos de pesquisa com elevado grau de excelência, focadas na área de pesquisa (research university), já localizados na região e que serão responsáveis pela formação e pelo treinamento de recursos humanos altamente qualificados (cientistas, engenheiros e técnicos), assim 
como por atividades de transferência de tecnologia e de pesquisas compartilhadas com as empresas e, ainda, pelo desenvolvimento de um espírito empreendedor entre seus pares e estudantes, para a formação de novas spin-offs (LINK; SCOTT, 2005).

Para Lindelöf e Löfsten (2003), a localização próxima a universidades e institutos de pesquisa permite às empresas estabelecerem links formais e informais, os quais encorajam a transferência de tecnologia e o desenvolvimento de inovações e ampliam a possibilidade de geração de empregos e bem-estar para a localidade. Em sua pesquisa, os autores identificaram que as empresas escolhem instalar-se em parques devido à proximidade com as universidades, proximidade com os mercados consumidores e a possibilidade de desenvolvimento de novos mercados.

Entretanto, para link e Scott (2007), a simples proximidade física entre empresas e instituições de desenvolvimento e pesquisa não garante a atuação estratégica conjunta dos participantes do parque. Esta depende de dimensões sociais, culturais e organizacionais. Para os autores, o principal motivo que afeta a decisão de uma firma em instalar-se em um parque tecnológico é o acesso às facilidades de pesquisa e aos cientistas das universidades. Nesse sentido, a chave para o sucesso do parque estaria em sua capacidade de desenvolver relações entre as firmas e as estruturas de desenvolvimento técnico-científico.

Em certo sentido, emerge como condição necessária a presença de comportamento empreendedor no território, que aparece como combinação e consequência da qualidade e quantidade de recursos humanos locais, e que incorpora dinamismo especial, focado em mudanças de cunho tecnológico e comportamental. Segundo lindelöf e Löfsten (2004), firmas localizadas em ambientes dinâmicos com elevado grau de processamento de informações, comunicação e transferência de conhecimento são mais propensas a desenvolver competências que resultem em inovações tecnológicas bem-sucedidas.

Por outro lado, a disponibilidade de recursos financeiros tem se apresentado como importante condição para o sucesso dos parques tecnológicos. Tal financiamento pode ser público e realizado por meio de bancos de desenvolvimento, de recursos não reembolsáveis ou até da utilização do seu poder de compra. Por outro lado, o setor privado desempenha papel essencial nesse tópico, seja disponibilizando recursos próprios para o empreendimento ou pela contratação de empréstimos e outras formas de financiamento bancário ou de capital de risco.

Ademais, é desejável que o empreendimento se realize em um ambiente macroeconômico proativo, gozando de estabilidade política e com uma estrutura regulatória favorável à atividade empresarial.
Permeando esses fatores-chave, há a questão da disponibilidade e interesse dos diversos agentes envolvidos de atuarem conjuntamente. A predisposição de cooperação e interação entre universidades, centros/ institutos de pesquisas, órgãos do governo federal, estadual e municipal, empresas e agentes financeiros é condição necessária para a implantação de um parque tecnológico por meio da formação de um sistema local/regional de inovação ou, nos termos de Florida (1995), a conformação de regiões de aprendizagem. Como argumentam Diniz, Santos e Crocco (2006):

\section{[...] os parques tecnológicos são ambientes capazes de estimular a criação tecnológica pela minimização dos custos de transação, associados a constrangimentos institucionais que dificultam, se é que não impedem, o desenvolvimento da colaboração e cooperação necessária à troca de conhecimentos tácita e codificada entre as organizações econômicas [...] (p. 98).}

Os participantes envolvidos no estabelecimento e operação dos parques tecnológicos possuem, pela sua natureza, diferentes perspectivas, percepções, interesses e necessidades que esperam atender por meio do empreendimento. Cada um possui sua própria agenda, a qual é, em alguns casos, repassada para os parques, quando um stakeholder possui força política e recursos para se impor aos demais participantes; nesse caso, o principal participante do empreendimento determina as metas e objetivos do parque tecnológico (GEENHUIZEN; SOETANTO, 2008).

Entretanto, ressalta-se que pela complexidade desse tipo de empreendimento, os parques tecnológicos, como já tratado, pressupõem competências e recursos que dificilmente poderiam ser providos por um único agente local. Nesse caso, a imposição de uma agenda específica poderia levar ao fracasso da iniciativa, pela ausência de condições necessárias. Assim, o mais provável, conforme a literatura, é de que a missão, metas e objetivos do parque sejam formados pela aglutinação das diferentes agendas dos envolvidos, gerando um conjunto multidimensional complexo (GEENHUIZEN; SOETANTO, 2008). Nesse sentido, não se trata de impor a vontade de um agente, mas da existência de um ou mais agentes que têm legitimidade e, principalmente, recursos para acomodar os diferentes interesses dos envolvidos.

No entanto, apesar da participação de diferentes agentes ser uma condição necessária ao sucesso na formação e consolidação dos parques tecnológicos, ela não é suficiente. Não há garantias de êxito no empreendimento, uma vez que a colaboração entre distintas organizações deve significar a agregação de diferentes ativos tangíveis e intangíveis. Em outros termos, a participação, por exemplo, de uma universidade que não possua atributos suficientes de atividades de pesquisa e desenvolvimento, assim como canais institucionalizados para o desenvolvimento de 
projetos cooperativos com o setor produtivo, pouco agregará para o sucesso do empreendimento (LINK; SCOTT, 2005). Sendo assim, não só é necessária a participação de diferentes atores locais na iniciativa como é necessária a presença de atributos específicos desses atores.

link e Scott (2007) especulam que as lacunas no entendimento da real natureza dos parques tecnológicos e seus condicionantes podem ser decorrentes da multiplicidade de procedimentos operacionais, objetivos e missões decorrentes da diversidade dos stakeholders. O que gera uma complexidade para o desenvolvimento de pesquisas focadas, a falta generalizada de métricas claras para medir os impactos e o desempenho dessas iniciativas e uma dificuldade de gerenciar os diferentes interesses e agendas de seus participantes. (LINK; SCOTT, 2007; LINDELÖF; LÖFSTEN, 2003).

Como argumenta Barquette (2002, p.102),

[...] não se constrói, em um local destituído de certos elementos locacionais, uma sociedade verdadeiramente inovadora, capaz de reproduzir e sustentar autonomamente a nova dinâmica do espaço.

A implantação e o desenvolvimento de parques tecnológicos dependem de condições históricas, sociais, culturais e da presença de infraestrutura de pesquisa previamente instalada, isso pode ser verificado pela heterogeneidade das diversas experiências, inclusive em termos de seus resultados e entidades participantes (LINK; LINK, 2003).

Assim, a formação de parques tecnológicos é um processo de dependência da trajetória (path dependence) e, portanto, idiossincrático, dificilmente passível de imitação, caracterizado pela especificidade de recursos e sujeito a fatores institucionais, limitando as iniciativas imitativas baseadas nas experiências pioneiras dos parques norte-americanos, os quais, como tratado, surgiram espontaneamente das precondições presentes anteriormente no território. Portanto, a coalizão de agentes em torno da proposta de instalação de um parque tecnológico, apesar de condição necessária, dificilmente será suficiente para garantir o desenvolvimento e o sucesso desse tipo de empreendimento.

Muitos autores argumentam que as regiões e seus atores locais podem propositalmente desenvolver as precondições citadas, uma vez que muitos dos recursos necessários para um ambiente inovador são dinâmicos, ou seja, trabalho qualificado, infraestrutura tecnológica, serviços ligados ao terciário avançado e a capacidade de interação e comportamento cooperativo entre os agentes são elementos determinados socialmente. No entanto, tais ações estão ainda condicionadas à dependência histórica de trajetórias socioculturais, econômicas e tecnológicas, as quais direcionarão as respostas mais ou menos eficazes às mudanças do macroambiente, de forma que não há garantia do sucesso da implantação futura de um parque tecnológico.

\section{Conclusões}

A mudança do paradigma técnico-econômico nos anos 1970 modificou profundamente a lógica de localização das empresas e de posicionamento das regiões na busca de desenvolvimento econômico sustentado. Nesse contexto, o êxito das regiões passa a depender de sua capacidade de especialização e de criação de vantagens comparativas efetivas e dinâmicas, decorrentes do estoque de atributos e da competência local de promoção continuada de inovação. Na atualidade, diversos autores têm tratado da dimensão local do desenvolvimento tecnológico, sendo que muitos deles têm desenvolvido análises sobre diferentes configurações produtivas regionais e sobre diversos instrumentos de apoio e adensamento da indústria de alta tecnologia.

Diversos mecanismos de suporte têm sido implementados tendo em vista o desenvolvimento e a geração de inovações, dentro os quais os parques tecnológicos se destacam desde seu surgimento espontâneo nos anos de 1940 até sua proliferação pelo mundo nas décadas de 1970 e 1980 . Com base em tais iniciativas de desenvolvimento regional deve-se procurar identificar os requisitos ou condicionantes para a instalação de parques tecnológicos que possam ser bem-sucedidos.

A literatura especializada apresenta um conjunto amplo e complexo de precondições necessárias para a formação e consolidação dos parques tecnológicos, dentre as quais: infraestrutura urbana e tecnológica, adensamento empresarial, disponibilidade de mão de obra com diferenciais de qualificação, existência de universidades e centros de pesquisa de excelência, comportamento colaborativo dos agentes, disponibilidade de recursos financeiros e de um ponto de vista supraterritoria - o ambiente de negócios e macroeconômico deve apresentar regras e instituições estáveis.

Por meio do exame de tais condições, o presente artigo procurou enfatizar algumas questões complexas que são em sua maioria pouco exploradas pela literatura focalizada em parques tecnológicos, tais como: (a) os limites da utilização dos parques como instrumentos de reconversão de regiões economicamente deprimidas; (b) a necessidade de uma escala mínima de aglomeração preexistente na região; (c) o caráter de dependência histórica (path dependence) de muitos dos elementos condicionantes do sucesso desses empreendimentos; (d) a importância da análise da estrutura política e seu papel na formação e consolidação desses 
instrumentos; (e) a natureza antagônica e a difícil gestão da participação e cooperação dos diferentes stakeholders envolvidos; (f) a necessidade de perceber que a participação de diferentes atores locais deve estar condicionada pela presença de atributos específicos desses atores; (g) a importância da existência de um ou mais agentes que disponham de legitimidade e recursos para acomodar diferentes interesses de todos os envolvidos no processo de formação e consolidação do parque tecnológico.

A simples opção de instalação de um parque tecnológico sem que sejam consideradas as precondições citadas na literatura representa um desperdício de recursos, por vezes escassos, os quais poderiam ser utilizados na construção das bases necessárias para uma futura instalação de empreendimentos do tipo. 0 perigo se concretiza quando a opção de instalação de parques tecnológicos se dá por motivos puramente políticos, sem a presença das condicionantes de sucesso. Em casos extremos, esses parques acabam se tornando simplesmente empreendimentos imobiliários empresariais de alto padrão.

Ressalta-se que os parques tecnológicos são apenas um dentre vários instrumentos que podem ser usados para encorajar a transferência de tecnologia e o desenvolvimento de firmas inovadoras. Para isso, há também incubadoras, consórcios de pesquisa, joint ventures entre pesquisadores e empresários, núcleos de inovação tecnológica, escritórios de patentes, licenciamento e transferência tecnológica, entre outros empreendimentos. Tais instrumentos podem ainda ser encarados como iniciativas, por parte dos atores locais, no sentido de criar as bases para a construção de parques tecnológicos futuros.

Cabe ainda destacar que as questões enfatizadas são essenciais para a análise de mecanismos de suporte ao desenvolvimento regional e necessitam ser aprofundadas para que peculiaridades do processo de formação e consolidação dos parques tecnológicos possam ser detalhadamente compreendidas. Entre outras, deve-se buscar maior compreensão do processo de cooperação entre diferentes atores locais, em especial como se inicia tal processo e quais as condições que possibilitam o sucesso dessa empreitada. Por outro lado, também se deve aprofundar a interpretação do papel das condições históricas locais no sucesso de iniciativas de desenvolvimento local, nesse sentido é relevante compreender se tais condições são impeditivas à realização de empreendimentos dessa natureza ou se são barreiras que podem ser superadas no processo de desenvolvimento. Esses questionamentos podem ser tomados como ponto de partida para pesquisas futuras. Concomitantemente, uma abordagem que merece ser mais explorada é a que trata de avaliações quantitativas do papel das regiões, e suas diferentes configurações, na formação e na consolidação dos parques tecnológicos nacionais, assim como a exploração de dados quantitativos dos próprios parques brasileiros. Entretanto, pesquisas futuras com foco no tratamento numérico dos parques irão requerer um conjunto amplo de informações métricas, as quais devem ainda ser elaboradas, uma vez que são raras e dispersas as informações dessa natureza sobre empreendimentos desse tipo localizados no Brasil.

\section{Referências}

ASSOCIAÇÃO NACIONAL DE ENTIDADES PROMOTORAS DE EMPREENDIMENTOS DE TECNOLOGIAS AVANÇADAS - ANPROTEC. Panorama 2003. Brasília: ANPROTEC, 2003.

APPOLD, S. J. Research parks and the location of industrial research laboratories: an analysis of the effectiveness of a policy intervention. Research Policy, v. 33, p. 225-243, 2004. http://dx.doi.org/10.1016/S00487333(03)00124-0

BARBIERI, J. C. Parques e incubadoras de empresas de base tecnológica: a experiência brasileira. FGV, 1995. Relatório de Pesquisa n. 4. Disponível em: <http://bibliotecadigital. fgv.br/dspace/bitstream/handle/10438/3193/Rel04-95. pdf? sequence $=1>$. Acesso em: 10 set. 2010 .

BARQUETTE, S. Fatores de localização de incubadoras e empreendimentos de alta tecnologia. Revista de Administração de Empresas, v. 42, n. 3, p. 101-113, 2002.

CASSIOLATO, J. E.; LASTRES, H. M. M. Glossário de arranjos e sistemas produtivos e inovativos locais. MDIC, 2003a. Disponivel em: <http://www.mdic.gov.br/arquivos/ dwnl_1289323549.pdf>. Acesso em: 20 jul. 2009.

CASSIOLATO, J. E.; LASTRES, H. M. M. O foco em arranjos produtivos e inovativos locais de micro e pequenas empresas. UFRJ, 2003b. Disponivel em: <http://www. ie.ufrj.br/redesist/P3/NTF2/Cassiolato\%20e\%20Lastres. pdf>. Acesso em: 20 jul. 2009.

CASTELLS, M.; HALL, P. Technopoles of the world: the making of twenty-first century industrial complexes. London: Routledge, 1994.

DIERDONCK, R. V.; DEBACKERE, K.; RAPPA, M. A. An assessment of science and technology parks: towards a better understanding of their role in the emergence of new technologies. MIT, 1990. Disponivel em: <http:// dspace.mit.edu/bitstream/handle/1721.1/46889/ assessmentofscie00dier.pdf? sequence $=1>$. Acesso em: 13 mar. 2011.

DINIZ, C. C. 0 papel das inovações e das instituições no desenvolvimento local. In: ENCONTRO NACIONAL DE ECONOMIA - ANPEC, 29., 2001, Salvador. Anais... Salvador, 2001. Disponivel em: <http://www.anpec. org.br/encontro2001/artigos/200105383.pdf>. Acesso em: 20 jul. 2009.

DINIZ, C. C.; GONÇALVES, E. Economia do conhecimento e desenvolvimento regional no Brasil. In: DINIZ, C. C.; LEMOS, M. B. (Orgs.). Economia e Território. Belo Horizonte: Editora UFMG, 2005. p. 131-170.

DINIZ, C. C.; SANTOS, F.; CROCCO, M. Conhecimento, inovação e desenvolvimento regional/local. In: DINIZ, C. C.; CROCCO, M. (Org.). Economia regional e urbana: contribuições teóricas recentes. Belo Horizonte: Editora UFMG, 2006. p. 87-122.

EUROPEAN COMMISSION. Regional Research Intensive Clusters and Science Parks. EC, 2007. Disponível em: 
<http://ec.europa.eu/research/regions/pdf/sc_park.pdf>. Acesso em: 25 maio 2011.

FERGUSON, R.; OLOFSSON, C. Science parks and the development of NTBFs - location, survival and growth. Journal of Technology Transfer, v. 29, p. 5-17, 2004. http://dx.doi.org/10.1023/B:JOTT.0000011178.44095.cd

FLORIDA, R. Toward the learning region. Futures, v. 27, p. 527-536, 1995.

FUKUGAWA, N. Science parks in Japan and their valueadded contributions to new technology-based firms. International Journal of Industrial Organization, v. 24, p. 381-400, 2006. http://dx.doi.org/10.1016/j. ijindorg.2005.07.005

GEENHUIZEN, M. V; SOETANTO, D. P. Science parks: what they are and how they need to be evaluated. International Journal Foresight and Innovation Policy, v. 4, n. 1-2, p. 90-111, 2008. http://dx.doi.org/10.1504/ IJFIP.2008.016908

INTERNATIONAL ASSOCIATION OF SCIENCE PARKS - IASP. About science and technology parks: definitions. IASP, 2002. Disponível em: <http://www.iasp.ws>. Acesso em: 01 set. 2010.

LAYSON, S. K.; LEYDEN, D. P.; NEUFELD, J. To admit or not to admit: the question of research park size. Economics of Innovation and New Technology, v. 17, n. 7-8, p. 689697, 2008.

LINDELÖF, P.; LÖFSTEN, H. Science parks and the growth of new technology-based firms - academic-industry links, innovation and markets. Research Policy, v. 31, n. 6 , p. 859-876, 2002. http://dx.doi.org/10.1016/S00487333(01)00153-6

LINDELÖF, P.; LÖFSTEN, H. Science park location and new technology-based firms in Sweden - implications for strategy and performance. Small Business Economics, v. 20 , p. $245-258,2003$.

LINDELÖF, P.; LÖFSTEN, H. Proximity as a resource base for competitive advantage: university-industry links for technology transfer. Journal of Technology Transfer, v. 29, p. 311-326, 2004. http://dx.doi.org/10.1023/ B:J0TT.0000034125.29979.ae

LINK, A. N.; LINK, K. R. On the growth of U.S. science parks. Journal of Technology Transfer, v. 28, p. 81-85, 2003.

LINK, A. N.; SCOTT, J. T. Opening the ivory tower's door: an analysis of the determinants of the formation of
U.S. university spin-off companies. Research Policy, v. 34, p. 1106-1112, 2005. http://dx.doi.org/10.1016/j. respol.2005.05.015

LINK, A. N.; SCOTT, J. T. U.S. university research parks. Journal of Production Analysis, v. 25, p. 43-55, 2006.

LINK, A. N.; SCOTT, J. T. The Economics of university research parks. Oxford Review of Economics Policy, v. 23, n.4, p. 661-674, 2007. http://dx.doi.org/10.1093/oxrep/ grm030

MEDEIROS, J. A. Pólos tecnológicos ilhas ou arquipélagos. São Paulo em Perspectiva, v. 9, n. 3, p. 80-86, 1995.

SCOTT, A. J.; STORPER, M. Indústria de alta tecnologia e desenvolvimento regional: uma crítica e reconstrução teórica. Espaço \& Debates, v. 3, n. 25, p. 30-44, 1988.

SIEGEL, D. S.; WESTHEAD, P.; WRIGHT, M. Science parks and the performance of new technology-based firms: a review of recent U.K. evidence and an agenda for future research. Small Business Economics, v. 20, p. 177-184, 2003a. http://dx.doi.org/10.1023/A:1022268100133

SIEGEL, D. S.; WESTHEAD, P.; WRIGHT, M. Assessing the impact of university science parks on research productivity: exploratory firm-level evidence from the United Kingdom. International Journal of Industrial Organization, v. 21, n.9, p. 1357-1369, 2003b. http:// dx.doi.org/10.1016/S0167-7187(03)00086-9

SPOLIDORO, R. A sociedade do conhecimento e seus impactos no meio urbano. In: PALADINO, G.; MEDEIROS, L. (Orgs.). Parques tecnológicos e meio urbano: artigos e debates. Brasilia: Anprotec, 1997. p. 11-54.

VARGAS, M. Proximidade territorial, aprendizado e inovação: um estudo sobre a dimensão local dos processos de capacitação inovativa em arranjos e sistemas produtivos no Brasil. 2002. Tese (Doutorado)-Universidade Federal do Rio de Janeiro, Rio de Janeiro, 2002. Disponível em: <http://www.redesist.ie.ufrj.br/>. Acesso em: 05 maiO 2011.

VEDOVELLO, C. A. Aspectos relevantes de parques tecnológicos e incubadoras de empresas. Revista do Banco Nacional do Desenvolvimento, Rio de Janeiro, v. 7 , n. 14 , p. 273-300, 2000.

VEDOVELLO, C. A.; JUDICE, V. M. M.; MACULAN, A.-M. D. Revisão crítica às abordagens a parques tecnológicos: alternativa interpretativa às experiências brasileiras recentes. Revista de Administração e Inovação, São Paulo, v. 3, n. 2, p. 103-118, 2006.

\title{
Theoretical approach of determining factors to establish and consolidate technology parks
}

\begin{abstract}
This article investigates the theoretical conditions to establish and consolidate technology parks, mechanisms used to promote innovation and economic development of regions - target of several current public policy initiatives. To achieve this objective a theoretical and exploratory approach was adopted through bibliographical review, particularly based on international references. The article presents and analyzes various concepts and definitions of technology park, and notes that this great diversity arises from different adjustments of the technology parks to different regional realities and to various motivations of its stakeholders. The role of the technology park in regional development assumes many features due to the varied interest of the players in installing these instruments in their territories. The article highlights and warns that there are important limitations of the idea that the success of the park depends crucially on the players' ability to cooperate and mobilize resources.
\end{abstract}

Keywords

Technology parks. Regional development. Technological innovation. Science and technology institutions. 